\title{
Las iglesias de Sepúlveda y sus santos titulares
}

\author{
Antonio Linage Conde
}

Como episcopus Segoviensis sedis firmó alguna vez el obispo de Simancas, la nueva diócesis erigida por Ordoño III hacia el año 952 '. Cierto que el territorio que entonces se le concedió consistía en la propia Simancas y su entorno y una parte del de Toro, de esa manera sustraído a las jurisdicciones de Astorga y León. Nada cerca, pues, de Segovia, la sede del obispado visigótico que además por aquellas calendas no era sino un recuerdo en el yermo, si bien hacía ya más de una década se había repoblado por el conde de Castilla Fernán González Sepúlveda, dentro de sus límites aunque bastante a un extremo.

Sepúlveda que, en esos comienzos, se ha conjeturado dependería sin embargo del obispo de Muño ${ }^{2}$, la mitra que en el territorio condal había venido a suceder a Amaya, durante una etapa que la evolución posterior nos hace ver cual un interludio al que la restauración de la de Oca en la nueva sede de Burgos pondría el punto final. Aunque, ¿hasta qué extremo el clero y los fieles de la aventura repobladora al filo de la frontera se integrarían en la normalidad canónica de la iglesia territorial?

C. SÁnchez-Albornoz: «El obispado de Simancas», Homenaje a Menéndez Pidal, 3 Madrid 1925, págs. 325-44; "estudio excelente y en plena vigencia a pesar de su fecha", acaba de escribir J.M. Ruiz AsENCIO, en la Historia de Valladolid II. Valladolid medieval, Valladolid 1980, págs. 33-6.

2 J.M. RuIz ASENCIO, ob. cit. en la nota anterior, pág. 36; cfr. D. Mansilla Royo, en la Historia de Burgos II. Edad Media, 1, Burgos 1986, 229-300; y G. MARTínez Diez: Los obispados de la Castilla condal hasta la consolidación del obispado de Oca, Burgos 1984, pág. 111. 
Pero estos detalles no nos interesan aquí. Lo que nos proponíamos era solamente atraer la atención hacia esa nostalgia de la tierra perdida y a la postre desertizada que nos revela agudamente esa titulación que de obispo de Segovia in partibus se daba el de Simancas. Y cuando decimos desertizada no tratamos de resucitar otra vez la polémica en torno al alcance de la despoblación del país. Baste a nuestros propósitos de hoy recordar lo que una vez nos escribiera don Jose María Lacarra de que «también el Sahara es un desierto y sin embargo hay saharianos» ${ }^{3}$.

Un pasado sacro, pues, dormido en parte y en parte perdido, en el contexto de la recíproca vinculación de la tierra y el hombre. Que cuando éste volvió a ésa hubo que despertar en unos casos y reconstruir en otros.

\section{LOS NUEVOS BRIOOS EN LA CONTINUIDAD}

El 20 de agosto de 1076, estando en Navares, aldea de Sepúlveda, Alfonso $\mathrm{Vl}$ otorgó escritura ${ }^{4}$ de donación al monasterio benedictino de Silos del «lugar que desde la antigüedad se llama de San Frutos, donde descansa el santísimo cuerpo de éste». Se trata del terreno de la ribera del Duratón y su cañón donde todavía quedan la iglesia y las ruinas del priorato que existió desde entonces hasta 1836.

Lo que nos interesa destacar de este acto es la permanencia que demuestra de una población sobre el terreno. Sólo ella habría podido mantener la memoria del siervo de Dios y de su tumba, gentes sin ninguna duda que habían resistido a la despoblación del país, ya que la hipótesis de adelantarlas a la repoblación de Fernán González, es inadmisible. Tanto ésta como la de Sancho García habían sido muy débiles, la primera cortada por la caída de la villa en poder de los musulmanes;

3 Para el caso concreto de que tratamos puede verse nuestro artículo "La donación por Alfonso VI a Silos del futuro priorato de San Frutos, y el problema de la despoblación», Anuario de Historia del Derecho Español, 41, 1971, págs. 973-1011.

${ }_{4}$ La publicó por primera vez M. FEROTIN: Recueil des chartes de l'abbaye de Silos, Paris 1897, págs. 23-6. 
y en cuanto a la segunda es decisivo el detalle de que el mismo rey Alfonso, al confirmarla el Fuero, el mismo año 1076, no menciona a su padre Fernando I entre los confirmantes anteriores - agudamente lo ha hecho notar Gautier-Dalché al estudiar nuestro «urbanismo» medieval-. Por otra parte la repoblación de Fernán sólo contaba entonces poco más de un siglo, demasiado poco para la solemnidad de ese ab antiquitate de la escritura alfonsina.

Y sin embargo de la repoblación del conde Sancho tenemos un testimonio pío en el mismo lugar santo. En una de las cuevas que se abren en la roca de la pared del cañón, donde estuvo la ermita de San Valentín, se han copiado grafitos con nombres de peregrinos cuya datación alternativa se ha propuesto el año 1029 o el $1059^{5}$. Por lo tanto un eslabón hacia el pasado anónimo y oral que únicamente el tardío diploma alfonsino elevaría por vez primera a categoría escrita.

Ahora bien, estas huellas del hombre en la tierra desertizada estaban en el campo, en el yermo incluso.

En cambio ninguna equivalente nos ha quedado en el casco urbano de Sepúlveda, en la población que con el nombre de Septempublica menciona por primera vez en la historia la Crónica de Alfonso III precisamente para darnos la noticia de su debelación y su eremación.

\section{LA CARA CRISTIANA DEL RETORNO HUMANO}

La huella religiosa gráfica y datada más antigua en la Sepúlveda repoblada es una inscripción de la iglesia del Salvador que consigna la fecha de $1093^{6}$, a más de siglo y medio, pues, de la repoblación de Fernán

5 J. Pérez de URBel: Historia del condado de Castilla, Madrid 1945, págs. 929 y 8346; y M. DE LA S. MARTÍN Postigo: San Frutos del Duratón. Historia de un priorato benedictino, Segovia 1972, págs. 200-2 y lám. XXXIV.

6 Aunque se ha pensado que sus toscos capiteles sean del siglo $x$, vueltos a aprovechar luego; V. LAMPEREZ Y ROMEA: Historia de la arquitectura cristiana española de la Edad Media, según el estudio de los elementos y los monumentos, $2{ }^{a}$ ed., Madrid 1930. Una inscripción litúrgica en una de sus piedras colocada en posición invertida, se ha dudado si es visigótica 0 del siglo $x$, en cuyo caso sería un vestigio de la Sepúlveda sacra de Fernán González; J. Pérez de URbel y A. González Rulz-Zorfilla. «Inscripciones litúrgicas. VIII-XIII, Liturgia 1, 1946, págs. $146-9$ y 175-8. 
González y casi veinte años posterior al otorgamiento de su Fuero por Alfonso $\mathrm{Vl}$ el repoblador definitivo. Coetánea parece haber sido la construcción de San Bartolomé ${ }^{7}$, y con bastante probabilidad la de San Millán, esta última en ruinas, de la que nos han llegado algunos capiteles cúbicos lisos o con molduras sencillísimas. La Virgen de la Peña y San Justo, también románicas, son algo más modernas ${ }^{8}$. Santiago, con huellas de fases sucesivas en su fábrica, parece haber sido en cambio anterior en su estado primitivo ${ }^{9}$. ¿Podríamos remontar sus cimientos, al menos, a la repoblación de Sancho García? No nos pronunciamos de momento ${ }^{10}$. De las demás iglesias, todas las arruinadas antes del siglo $\mathrm{xIX}$, no nos quedan restos bastantes para conjeturar su datación.

$Y$ el documento más antiguo que las enumera todas, las quince parroquias ${ }^{11}$, que la villa tuvo, es ya tardío, de $1295^{12}$. Pero ningún indicio deja de apuntar casi con seguridad plena a la contemporaneidad de las mismas estre sí y con la repoblación alfonsina, pues era inconcebible que quedaran dentro del recinto amurallado, cuyo perímetro aquéllas punteaban fielmente, vacios parroquiales y eclesiales, y la despoblación actual pero desde luego remota de la mayor parte de aquél - todo el Oeste, pero tomado con amplitud abrumadora-, con las feligresías de San Juan, Santa Eulalia, San Martín y San Sebastián ${ }^{13}$, refuerza la in-

7 Marqués de Lozoya: Sepúlveda, Segovia 1967, pág. 20.

8 Consta epigráficamente que la torre de la primera se empezó a edificar en 1144. Pero luego diremos de la quizás anterior bóveda de San Justo.

9 Es muy interesante el estudio incluido en el inédito "Anteproyecto de rehabilitación para Centro Cultural de la Villa" de los arquitectos José Mata Wagner y Luis de Villanueva (Segovia, enero de 1988). Esta iglesia se derrumbó durante la guerra civil, aunque no a consecuencia de la misma.

10 Es curiosa la coincidencia de esta mayor antigüedad con la tradición que recoge el canónigo Horcajo, de quien luego diremos, de haber sido la primera iglesia de la villa cuando ésta fue cristianizada, y su solar vivienda de sus primeros predicadores. Otro dato es que la capilla de Santa Lucía, aneja a la misma, era municipal y sede del archivo.

11 E. SAEZ da noticia de la Concepción; Los Fueros de Sepúlveda, Segovia 1953, pág. 884, nota 1, por haberla visto mencionada en un inventario del Archivo Histórico Nacional. No hemos encontrado vestigio alguno de ella. En todo caso su advocación difícilmente puede ser medieval. Tampoco es posible la confusión con la Virgen de la Peña, ya que la advocación de ésa era la Asunción, aunque por las necesidades laborales en su fiesta del 15 de agosto de los campesinos de la comarca ésa se trasladó al 29 de septiembre, coincidiendo, pues, con el día de San Miguel.

12 Texto en E. SÁEZ: Colección diplomática de Sepúlveda. I, Segovia 1956, núm. 13, págs. 46-8; sigue el impreso por Horcajo, quien suplió sus lagunas con arreglo a sus conocimientos locales -ipero apenas archivisticos!-, único posible, ya que se ha perdido el original que aquél vio en 1910 en el Archivo Parroquial.

${ }_{13}$ Si bien en el centro del perímetro formado por el casco actual y los solares de las antiguas iglesias hoy en despoblado queda un vacío parroquial -además del dicho del 
compatibilidad con una datación bajomedieval de los tales templos, sobre todo si nos paramos a reflexionar en que la población no intensificaría precisamente su pujanza al perder su significación fronteriza cuando, muy tempranamente para ella, Toledo fue definitivamente incorporado por Alfonso $\mathrm{VI}$ a la cristiandad el año $1085^{14}$. Por otra parte se advierte que las iglesias estaban situadas periféricamente, siguiendo la muralla, aunque con menos densidad en el norte y un vacío al noroeste, lo cual desde luego nos revela un plan «¿urbanístico?» ${ }^{15}$.

Tres de las parroquias estaban extramuros, San Bartolomé, San Gil y Santo Domingo, todas al extremo sureste del casco, donde hoy está la Plaza Mayor y una buena parte de la población que queda, justamente pues a la máxima distancia de ese noroeste vacío de dentro de la muralla. Pero tengamos en cuenta que San Bartolomé es de las más antiguas entre todas, como hemos dicho. Por eso hay que excluir una datación moderna a las tales fuera del recinto, situación ésta que por otra parte nada excepcional hace dicha cronología temprana sino que, en contra de lo que a primera vista podría parecer al profano, es ordinaria en el urbaismo medieval de las ciudades-fortaleza. Aparte que, en cuanto a Sepúlveda, ya hemos intuido e incluso visto que no parecía ser el espacio lo que dentro debía escasear. Un espacio que la orografía había prefabricado demasiado vasto quizás.

Pero ocupémonos ya sin más de las iglesias y sus santos titulares.

\section{LAS QUINCE PARROQUIAS ${ }^{16}$ Y SIETE ERMITAS}

El casco actual de Sepúlveda tiene la forma de una $Y$ invertida que ocupa solamente la periferia oriental y aproximadamente una tercera

noroeste- donde sólo es posible estuviera San Martín, de localización imprecisa aunque al oeste de El Salvador; véase el libro citado en la nota 10, págs. 883-7 y fotografía aérea comentada.

14 A. Linage Conde: "La dimensión militar en la historia. A propósito de la villa de Sepúlveda", Religión y Cultura, 29, 1983, págs. 453-97.

${ }_{15} Y$ hay que tener en cuenta que el recinto amurallado venía muy determinado por la configuración del terreno, o sea la península entre los valles encañonados del Duratón y su afluente el Caslilla que al oeste de la misma desemboca en él. Por eso no podemos pensar en un ensanchamiento a propósito para cobijar los ganados en caso de peligro; cfr. J.M. LACARRA: "Les villes-frontières dans l'Espagne du Xl ${ }^{\circ}$ et XIl ${ }^{e}$ siècle», Le Moyen Age, 69 (volume jubilaire, 1888-1963) pág. 205-22.

${ }_{16}$ E. HORCAJO MONTE: Historia y piadosas tradiciones de la sagrada imagen de la santi- 
parte de la periferia meridional del recinto amurallado y, como ya dijimos, se sale de éste por el extremo sudoriental.

En este casco se situaban de norte a sur la Virgen de la Peña, San Millán, San Sebastián, San Justo y El Salvador; al Este, pero ya fuera de muros, San Bartolomé, San Gil y Santo Domingo; y al Oeste Santiago, San Esteban y San Andrés. En la parte hoy despoblada estaban San Pedro, aislado al norte, y San Juan y Santa Eulalia al sudoeste. San Martín es la de localización menos exacta, al oeste de El Salvador y quizás la de ubicación menos periférica, o sea en el vacío central que desde luego ocupaba la mayor parte del recinto.

Había además seis ermitas: San Cristóbal, sobre la cumbre más elevada o Somosierra, en el centro del ensanchamiento que el recinto forma al Oeste, antes casa de caridad y hoy cementerio ${ }^{17}$; la de la cofradía de la Transfiguración del Señor, junto a la puerta de la muralla llamada de Duruelo; y tres fuera de muros, a saber las del hospital de Santa Cruz y San Lázaro, San LLorente y San Adrián. San Marcos, única en pie anunque reedificada y cambiada de emplazamiento en 1810, en el arrabal de Santa Cruz, está también fuera de la villa. Además, en una imponente península sobre el cañón del Duratón ${ }^{18}$, en término de Castrillo de Sepúlveda, tienen todavía alguna consistencia las ruinas de la románica de San Julián.

sima Virgen María que con el título de la Peña se venera en la villa de Sepúlveda y su tierra, y de su santuario, Madrid 1910, págs. 133-41. El canónigo Horcajo dejó inédito un estudio titulado Templos de la villa de Sepúlveda, datado el 1902. Debemos su consulta, cuando le dábamos por perdido y ninguna noticia teniamos de él, al comandante médico de la Armada don Pablo Román Molinero. Sobre Horcajo como historiador hemos tratado en "Alfonso I en Sepúlveda. La mención de "Septempública" en la "Crónica de Alfonso III"' ", Asturiensia Medievalia, 3, 1979, pág. 105-38; y "Un canónigo sepulvedano de León: don Eulogio Horcajo Monte (1840-1912). En torno a la iglesia española del ochocientos", Naturaleza y gracia, 28, 1981 , págs. $7-84$, sobre todo págs. 121-2 y 76-83 respectivamente.

17 No es posible encontrar ningún fundamento en las fuentes ni lógica en la situación que éstas permiten reconstruir un poco de que aquí estuviera antes la plaza. Por nuestra parte no negamos que la persistencia de esa tradición oral, aparentemente tan gratuita, da sin embargo más que pensar por eso.

${ }_{18}$ Dejando la carretera del Villar de Sobrepeña a Sepúlveda y tomando un sendero que sale a la izquierda a la altura de las canteras se tiene una imponente vista enfrete de esta ermita. 


\section{LOS CONSTRUCTORES Y ARTISTAS}

La bibliografía sobre el románico sepulvedano se inicia el año 1900 con un estudio concreto de Enrique Serrano Fatigati ${ }^{19}$, un profesor de ciencias e ingeniero ferroviario atraído por la historia del arte hasta llegar en su campo a una erudición paciente. Poco después, el arquitecto Vicente Lámperez y Romea aludía a aquél en una de sus obras de conjunto ${ }^{20}$, camino por el que seguirian Manuel Gómez Moreno ${ }^{21}$, Gudiol y Ricart y Gaya Nuño ${ }^{22}$, y el marqués de Lozoya ${ }^{23}$. llustres nombres en verdad, pero que se conformaron con una descripción de las formas encontradas en las iglesias de la villa y el establecimiento de sus analogías con otras anteriormente ofrecidas por el estilo. Un reciente libro de Inés Ruiz Montejo ${ }^{24}$ ha nacido ya con otras aspiraciones, que le han permitido suscitar inquietudes nuevas, pues además de insistir dentro del aspecto formal en la densidad iconográfica ${ }^{25}$, se ha propuesto superar la catalogación material aunque paralela, investigando en lo posible los talleres del país y la localidad que fraguaron los dichos templos ${ }^{26}$.

Inés Ruiz, luego de sentar ${ }^{27}$ que las iglesias de El Salvador de Sepúlveda y el priorato de San Frutos son anteriores a las de San Esteban de Gormaz, o sea las otras románicas más antiguas de esta cuenca sur del Duero medio, opina que ambas tuvieron su origen en un maestro de fuera, próximo al camino de Santiago, quien habría sido personalmente el autor de El Salvador, en tanto San Frutos sería ya obra inmediata de

19 «Excursiones arqueológicas por tierras segovianas", en el Boletín de la Sociedad española de Excursiones.

20 Historia de la arquitectura cristiana española de la Edad Media según el estudio de los elementos y los monumentos, II, Madrid 1906, págs. 76-7, de la 2.. ed., 1930.

21 El arte románico español. Esquema de un libro, Madrid 1934, págs. 152-5.

22 «Arquitectura y escultura románicas", tomo $V$ del ARs Hispaniae. Historia general del arte hispánico, Madrid 1948, págs. 296-8.

23 El románico segoviano, Segovia 1967, pág. 17, lleno de sugerencias.

${ }^{24}$ El románico de villas y tierras de Segovia, Madrid 1988.

25 En este ámbito el libro de M. GueRRA: Simbologia románica. El cristianismo y otras religiones en el arte románico, $2 .^{2}$ ed., Madrid 1986, aunque no se ocupa mucho de Sepúlveda, cuando lo hace tiene el interés de subsumir su imaginería en los grandes temas universales. Véase también (para la iglesia de Duratón), M. RuIz MALDONADO: «El caballero en la escultura románica de Castilla y León», Acta Salmanticensia, Filosofía y Letras, 177; Salamanca 1986, págs. 96-8.

${ }_{26}$ Ya en el prólogo a la obra de Ruiz Montejo nota J.M.DE AZCÁRATE la diferencia entre ambos planteamientos.

27 Págs. 17-61 de su libro; antes en Goya, núm. 158, págs. 87-93. 
artesanos locales más toscos. $Y$ aventura la hipótesis de si este maestro sería un benedictino, el dom. Michael que aparece en la inscripción de la consagración de la iglesia del priorato. Un paso más hacia la identificación, que le hace constructor de la colegiata de Elines, en Cantabria, y originario de Tournus, es la conjetura de María Eálo de Sá ${ }^{28}$.

Inés propone también la identificación de un taller en el pueblo de Duratón, otro en Fuentidueña - a orillas del río Duratón aún - al que se debería el pórtico de El Salvador, y uno ya de tierras de Segovia al que adscribe las iglesias sepulvedanas de la Virgen de la Peña y los Santos Justo y pastor, si bien con huellas también del anterior y habiendo acaso tenido la simbiosis en la misma Sepúlveda.

Nosotros no tenemos aquí ningún propósito de adentrarnos en este terreno artístico. Lo que tratamos es de llamar la atención acerca de la historia religiosa de la Sepúlveda renacida. Y por eso, de aquel ámbito nos interesa sólo detectar la procedencia y consecuentemente el acervo sacro de los repobladores y artífices. De ahí que hayamos de volver un tanto a los estudios descriptivos anteriores, aunque sin perder de vista esa su tan creativa elaboración por Ruiz Montejo. Y por más que algunos se nos escapen un tanto-concretamente estamos pensando en la impronta cisterciense que Gómez Moreno vio en los capiteles altos de la torre de la Virgen de la Peña. Claro está que, por los imperativos de la cronología, únicamente tendríamos que considerar el primer taller, pues los otros tres nos llevan ya hacia el XIII, época de la villa desde luego no repobladora. Sin embargo no creemos útil una exclusión rígida, en cuanto es presumible una cierta permanencia de las corrientes y conexiones culturales y geográficas de los orígenes en el desarrollo posterior. Habiéndose además de tener muy en cuenta la posible existencia en las iglesias posteriores de elementos subsistentes de una fase previa de las mismas. Por ejemplo a la bóveda esquifada de la torre de San Justo la tienen por anterior a la correlativa de El Salvador Gómez Moreno y Torres Balbás ${ }^{29}$. Lo que nos debe hacer recordar por supuesto una vez más que no contamos con más documentos que los restos de la misma plástica y que la discusión está abierta en cuanto a la interpretación de

${ }^{28}$ El románico de Cantabria en sus cinco colegiatas, Santander 1978, págs. 256-7. Para el contexto de la significación del injerto monástico en este ámbito concejil, A. LINAGE CONDE: «Un caso de la colonización benedictina: la repoblación de Sepúlveda», Cistercium, 32, 1980, págs. 205-22.

29 "La progenie hispano-musulmana de las primeras bóvedas nervadas francesas y los orígenes de las de ojivas", Al Andalus, 1935, pág. 409. 
los que entre ellos puedan salirse de la datación de los conjuntos donde se integran.

Pero entrando ya en nuestra materia, ante todo nos interesa valorar el aporte islámico. En El Salvador hay algunos elementos aislados de tradición mozárabe, y fuera de la villa se encuentran portadas con arcos lobulados en las iglesias de algunos pueblos del alfoz. Ruiz Montejo piensa que aquéllos podrían sencillamente seguir atribuyéndose al maestro del taller, en cuanto esas formas islámicas se conjugaban ya con las cristianas en esas sus calendadas tierras de posible origen. Para las segundas, la hipótesis genérica de René Crozet ${ }^{30}$, es la de su procedencia mediata, a través del románico francés ${ }^{31}$, que había dado previamente entrada a lo califal ${ }^{32}$. Ruiz Montejo ${ }^{33}$, se inclina a esta mediatez, si bien no está conforme sin más con ese paso por Francia, pues piensa pudo llegar a Sepúlveda desde León ${ }^{34}$, lo cual coincidiría con todo el contexto de la villa y su tierra ${ }^{35}$.

Pero de lo que no hay duda es de que una inmigración de cristianos mozárabes ${ }^{36}$, en posesión de una cultura capaz de influir en sus correligionarios del norte, cual la que se dio en el León del siglo $x$, no tuvo lugar en estas tierras de Sepúlveda durante ninguna de las fases de su repoblación.

Así las cosas, los caminos por explorar son los septentrionales ${ }^{37}$. Ya nos han salido Francia y el de Santiago — «camino francés»- también.

so «Etudes hispano-limousines», Boletín del Seminario de estudios de arte $y$ arqueología, Universidad de Valladolid, 1953-4.

31 Del centro y el sur, pero sobre todo en torno a Limoges.

32 En el fondo es lo que vio Gómez Moreno, precisamente a propósito de las bóvedas esquifadas de El Salvador y San Justo, al negar el influjo francés inmediato pero sugerir de paso la ascendencia mozárabe de la crucería francesa.

33 «La influencia islámica de algunas puertas románicas de la cuenca del Duratón», Actas del XXIII Congreso internacional de Historia del Arte. España entre el Mediterráneo y el Atlántico. Granada, 1973, Granada 1976, págs. 179-82.

${ }^{34}$ Está presente en San Isidoro.

${ }_{35}$ Hace notar la que en otro caso sería paradójica ausencia de este elemento islámico en el románico de ladrillo de Cuéllar; y la impresión que da el Fuero de la condición servil de sus moros, a diferencia de sus comunidades libres en otros concejos, propicios al cultivo de la albañilería y el artesonado. Si bien en cuanto a éste no hay que olvidar las cubiertas a par y nudillo de Santiago y San Justo.

${ }^{36}$ La parsimonia de las huellas moriscas ha llevado a L. M. DE LOJENDIO a distanciar Sepúlveda en ese sentido de San Estéban de Gormaz; Castille romane, II (La Pierre-quiVire, 1966), págs. 116-119.

${ }_{37}$ Curiosamente los paralelos abulenses que se han señalado por Gómez Moreno se localizan todos en la Virgen de la Peña y son iconográficos. 
Y acabamos incidentalmente de toparnos con León. Dos conexiones que Gómez Moreno destacó por algunos otros elementos, aparte los que dejamos citados: los pilares que refuerzan las bases de la torre de El Salvador, de abolengo en San Isidoro, así como las columnillas también de refuerzo de los ábsides, por una parte y por otra las arquerías ciegas interiores, que le hicieron pensar tanto como en construcciones asturianas ramirenses en otras provenzales.

Y también Lámperez había traído a colación lo asturiano, a propósito de la estructura de El Salvador, que le recordó «en cierto modo la latinobizantina de Santa Maria de Naranco".

Pero nos queda todavía el aporte más indiscutible e intenso, el aragonés. A la bóveda esquifada de El Salvador que ya mencionamos, Gómez Moreno seguido por Gudiol y Gaya le da una ascendencia jaquesa ${ }^{38}$; y el marques de Lozoya ${ }^{39}$ se acordaba también de Jaca ante las torres de El Salvador y la Virgen y la portada de ésa ${ }^{40}$. Y Gudiol y Gaya han ido todavía más lejos al hacer derivar el románico de El Salvador y San Frutos sin más del ya degenerativo de Loarre y su secuela, en lugar del burgalés más próximo.

Ahora bien, estas huellas aragonesas no pueden estar más puestas en razón para la fase post-repobladora, la cual se puede hacer si no coincidir sí entroncar con la cronología de la Virgen de la Peña, pues Alfonso I, luego de vencer en la batalla de Candespina, cerca de la villa, el año 1111 , todavía dominaba Sepúlveda en $1118^{41}$, habiéndole sido muy fieles sus caballeros pardos hasta última hora en aquellos confines de la Extremadura castellana. $Y$ los indicios apuntados de una presencia

${ }^{38}$ Gudiol y Gaya recuerdan también su coincidencia con la de la torre vieja de la catedral de Oviedo; Gómez Moreno también piensa en Jaca a propósito de la otra bóveda esquifada, la de San Justo.

39 "Influencias aragonesas en el arte segoviano", Seminario de arte aragones, 5, 1953, págs. 7-11.

${ }_{40}$ Cfr. para reforzar la identificación del origen J.M DE AZCARATE: "Sincretismo de la escultura románica navarra", Príncipe de Viana, 37, 1976, pág. 131-50. Azcárate insiste en la impronta jaquesa del disco encuadrado por dos figuras que se coloca en el tímpano de la portada. La influencia inmediata navarra fue señalada por Gómez Moreno en los capiteles también de la Virgen de la Peña.

41 J.M. LaCARRA: Vida de Alfonso el Batallador, Zaragoza 1971, págs. 42-5 y 74-5. El marqués de Lozoya por su parte había señalado la índole más bien aragonesa de la diócesis de Sigüenza entonces; cfr. I.G. BANGO ToRviso: «El maestro de Grado del Pico: un maestro románico aragonés en Castilla", Actas citadas en la nota 33, págs. 283-91. 
de tales trazas con anterioridad nos dejan al menos conjeturar una cierta continuidad en las mismas, la que desde luego habría implicado un desbordamiento cuando la victoria militar del rey aragonés y las vicisitudes del intervencionismo castellano de su política matrimonial le llevaron a protagonizar durante el período dicho la historia sepulvedana.

Sentada, pues, ya la progenie norteña ${ }^{42}$ de su construcción y decoración, volvamos a las iglesias de la villa sin cuidarnos ya de su encarnación plástica.

\section{LOS SANTOS TITULARES}

Una de las parroquias de Sepúlveda está dedicada al Salvador y otra a la Virgen bajo una advocación local tomada del elemento geográfico que más caracteriza el pueblo, la Peña. También tiene la suya el precursor, San Juan Bautista. Cuatro llevan nombres de apóstoles, San Pedro, Santiago, San Andrés y San Bartolomé. Y una el del protomártir San Estéban. Y San Sebastián es un mártir cuya popularidad universal se explica de por sí en ésta como en cualquiera otras tierras.

De los otros santos hemos en cambio de decir algo que nos justifique esa su presencia medieval sepulvedana. Dos de ellos son regionales, pero además su culto tenía allí una motivación muy concreta. Se trata de San Millán y Santo Domingo de Silos.

El año $1086^{43}$ el abad de San Millán de la Cogolla, Alvaro, consigna por escrito la posesión de una serna en el alfoz de Sepúlveda ${ }^{44}$ que le

42 En un escritor sugerente hasta el apasionamiento leemos: «Lo que llama la atención en la iconografía sepulvedana de El Salvador es la síntesis estética de dos concepciones diferentes del arte; la nórdica y la occidental»: MARCIANO SÁNCHEZ: Vida popular en Castilla y León a través del arte, Valladolid 1982, págs. 29-32.

43 Texto en E. SÁEZ, ed. cit. en la nota 11, núm. 2, págs. 173-4.

44 Véase T. Calleja GUIJARRO: "Donaciones segovianas medievales al monasterio de San Millán de la Cogolla", Estudios en homenaje a don Claudio Sánchez-Albornoz en sus noventa años. Anexos de Cuadernos de Historia de España II, 1983, págs. 399-418; para la significación económica del acto, J.A. Garcia DE CORTAZAR y RUIz DE AguirRE: El dominio del monasterio de San Millán de la Cogolla (siglos $x$ al XIII. Introducción a la historia rural de la Castilla altomedieval, Salamanca 1969, pág. 262. Del monasterio en cuestión se ha escrito que "su contribución a la formación de la nacionalidad española la podemos encuadrar entre Segovia, Sepúlveda, Zaragoza y Pamplona»; J.B. OLARTE: "Apuntes para una interpretación de la historia emilianense", Boletín de la Provincia de San José de los Agustinos Recoletos, 25, 1973, San Millán de la Cogolla en su XV centenario, págs. 53-65. 
había en su día dado el merino Pedro Juan con móviles repobladores, y le había confirmado el propio rey Alfonso VI por medio del senior Diego Téllez que mandaba en la villa, saliendo al paso de una usurpación.

En cuanto a Santo Domingo de Silos recordemos que murió el año 1073 como abad de monasterio que inmediatamente pasaría a llevar su nombre ya culturizado, o sea el maius del priorato de San Frutos y por ende uno de los protagonistas de la repoblación sepulvedana. Hay que excluir que se trate de santo Domingo de Guzmán, no solamente por la cronología más tardía de éste, sino por la mayor vinculación de su culto a su orden religiosa, de génesis no regional, y en consecuencia no inicialmente tan popular precisamente en torno a su Caleruega nativa. En cambio, en cuanto al Silense, aparte esa conexión concreta, se convirtić desde un principio en una de las estampas pías más difundidas en la tierra.

Los titulares de otras dos parroquias, por su parte, nos llevan al sur, a ese mediodía que habíamos descartado como zona de procedencia de nuestros repobladores sacros y profanos si la expresión se nos permite. Son los Santos Justo y Pastor -San Justo que se simplifica en la apelación normal- y Santa Eulalia, mártires los tres hispanos en la época romana. Pero su culto se había difundido tanto en toda España y aun fuera antes de la invasión musulmana que sería ingenuo abogar por una introducción del mismo en Sepúlveda partiendo de sus tierras de procedencia.

Por otra parte en cuanto a los citados santos niños de Alcalá ${ }^{45}$, su devoción en Castilla y León se intensificó después de la batalla de Simancas, por haber tenido lugar esta victoria en torno a su fiesta del seis de agosto. Simancas que es el evento de la reconquista ligado inmediatamente a la repoblación de Sepúlveda, tanto que llega a botón de muestra para ejemplificarnos la relación in genere del uno y del otro proceso.

Salvo esta última coincidencia lo mismo cabe decir de Santa Eulalia de Mérida, ya que de ésta y no de la de Barcelona ha de tratarse. No vamos a aludir aquí a la polémica de si las dos santas pueden reducirse

45 G. García Rodríguez: El culto de los santos en la España romana y visigoda, Madrid 1966, págs. 253-7; en relación con Sepúlveda alude al tema en su tesina inédita $M$. Gasca Alcolea: La iglesia de los Santos Justo y Pastor de Sepúlveda, Sección de Arte Medieval, Facultad de Geografia e Historia, Complutense. 
a una y la misma ${ }^{46}$, pero teniendo en cuenta la índole muy tardía y parsimoniosamente local del culto a la barcelonesa y el mucho mayor predicamento de la emeritense, quizás incluso en la propia Barcelona donde ésta tuvo tres iglesias-, la identificación de la sepulvedana no puede ser más obvia.

Y nos faltan San Martín y San Gil. Del primero, el vir dei de Panonia, de tan desorbitada popularidad en Francia y todo el Occidente, el santo de la máxima densidad cultual y hagiotoponímica, nada hemos de explicar, pues sabedores de la geografía histórica sepulvedana en aquella hora, esta circunstancia nos inhibe de cualquiera encuesta concreta.

En cuanto a San Gil, éste históricamente no era sino un monje o ermitaño del siglo VI o el VIII de cuya sencilla vida nada se sabía, pero que por haber sido enterrado en el monasterio al cual dio el nombre, Saint-Gilles, puerto junto al pequeño Ródano, y a su vez embrión de la ciudad a la que también transmitió la denominación, alcanzó una popularidad muy amplia, a cuya difusión contribuyeron los peregrinos a Santiago y a Roma que por allí pasaban, en el que acabó incluso siendo conocido por "el camino de Saint-Gilles" ${ }^{47}$. Su presencia en Sepúlveda no hace naturalmente sino reforzar lo trascendente del norte transpirenaico dicho. Recordemos las conexiones artísticas provenzales de que dejamos dicho.

Aún hemos de decir de San Julián, el titular de la ermita sobre el cañón ${ }^{48}$. Nos inclinamos por los Santos Julián y Basilisa, los esposos vírgenes y mártires quizás de Antinoe en Egipto, pero más conocidos por de Antioquía y en todo caso de pormenorización poco segura, festejados el nueve de enero ${ }^{49}$. Si bien no podemos excluir sin más fuera el mártir

46 Favorables a la identificación fueron los Bolandistas: H. MORETUS: «Les saintes Eulalies", Revue des questions historiques, 89, 1911, págs. 85-119. A la duplicidad F. FITA: "Santa Eulalia de Barcelona", Boletín de la Real Academia de la Historia, 43, 1903, 250-5; y A. Fábrega Grau, libro con el mismo título, Roma 1958, a propósito de este y otros trabajos del autor sobre el tema; cfr. B. DE GaIFFIER: «Sub Daciano praeside», Analecta Bolandiana, 72, 1954, págs. 383-9 y en Ibidem. Hispana et Lusitana, 77, 1959, y J. VivES, "Hispania sacra», 10, 1957, págs. 490-1. Mucha bibliografía en BENEdictins de PaRIs: Vies des saints et des bienhereux, Paris 1956, págs. 315-6.

47 Pueden verse los dos libros de E.C. JONES: Saint Gilles. Essai d'histoire littéraire, París 1914, y F. Brittain: S. Gilles, Cambridge 1928.

48 San Marcos, San Lázaro, San Lorenzo y San Cristóbal son santos de difusión devocional común y no nos plantean problema alguno.

49 Ya dijimos de la otra ermita sepulvedana, San Adrián. También correspondiente a otro matrimonio virgen de mártires, los Santos Adrián y Natalia, de Nicomedia. 
de ese nombre celebrado el siete de enero y del todo incógnito, pero que a pesar del tal desconocimiento integral de toda su vida alcanzó cierta popularidad devocional en Occidente. Desde luego no puede tratarse de San Julián de Toledo, pues un arzobispo escritor del otro lado de la cordillera y que murió en la cama, a pesar del traslado de su cuerpo a Oviedo en los días de Abderrahmán ${ }^{50}$ no era apenas posible despertara la devoción repobladora norteña. $Y$ tampoco se puede pensar en San Julián el Hospitalario, el protagonista de las páginas quizás más espeluznantes de la Leyenda Dorada, pues a pesar de su presunto origen aragonés - el nacimiento era italiano- no consta de su culto en el país.

Y termina nuestro excursus. De aquella tierra desertizada donde sólo algunos pastores y labradores habían mantenido la memoria del santo ermitaño Frutos en unas soledades que llegaron con mucho a seculares, la Sepúlveda urbanamente repoblada había llegado a la urdimbre de una hagiografía tan densa como representativa, cuando el año 1107 la erigió en diócesis Alfonso VI. Y si bien poco después, en 1122, quedaría absorbida en la restaurada de Segovia, San Frutos sería el patrón de ésta, pasando así de la devoción campesina del cañón a los esplendores pontificales de la catedral ${ }^{51}$.

Renacida Sepúlveda con una vocación indefectiblemente militar, el temprano alejamiento definitivo de su frontera al otro lado del lejano Tajo, la quitó protagonismo en la historia. $Y$ sus iglesias permanecieron brizando la dormición vagarosamente ensoñada de sus feligreses. Todavía se mantenían en pie todas el año 1689: "Que el día del glorioso apóstol San Pedro, abogado y patrón del cabildo, salía procesionalmente de Santiago a Santa María, y desde allí se dirigía a la iglesia del dicho señor San Pedro, donde hacía el oficio divino y cantaba la misa mayor». Así empezaban sus estatutos aprobados en la fecha.

La tradición quiere que cuando sin dejar una vuelvan a doblar a muerto la noche de las ánimas volverán a la villa los días de gloria. A mí en este trance, la nostalgia que la evocación de tanta desolación deja me consuela la entrañable destinación de estas páginas.

50 Alli dio nombre a la localidad de Santuliano, hoy un barrio de Oviedo.

51 A. LINAGE CONOE: "La erección de los obispados de Cuenca y Sepúlveda en el contexto de la repoblación foral», Cuadernos de Historia de España, 69, 1987, págs. 25-40. 